\title{
Factors Influencing Primary School Non-attendance among Children in North West Nigeria
}

\author{
Hadiza Korau Shehu \\ University of Aberdeen, Scotland, UK
}

\begin{abstract}
This paper presents a study that investigate the effects of children, household and state factors on primary school non-attendance among children in North West Nigeria. The study uses a nationally representative dataset, the Nigerian Education Data Survey (NEDS 2010) to investigate how children, household and state factors affect primary school non-attendance among children. The data pertaining to the area under study was extracted from the NEDS 2010 dataset and prepared for analysis. The study then uses multilevel analysis to hierarchically examine the effects of children, household and state factors on primary school non-attendance in North West Nigeria. The results of the multilevel analysis showed that most of the strong determinants of primary school non-attendance was due to household factors, with parental education and wealth being the most important. The results further showed that parental education and wealth also influences other factors across children, household and state levels. The results also showed that distance to school has more influence on primary school non-attendance among state factors.
\end{abstract}

\section{Introduction}

Education as a fundamental human right has been enshrined in a number of international normative frameworks and built into most national legislation [1]. In the recent years, the universal primary education has gained an increasing interest across the globe for various reasons. One of the reasons is that education is amongst the most important factors that determines the increase of economic growth and development of a country [1]. Primary education has been clearly highlighted by various international policies as an important foundation for further learning and development of children, irrespective of gender, socio-economic status and place of residence [4]. The importance of promoting universal primary education across the world led to the organization of a conference for the World Declaration on Education for All (EFA), Millennium Development Goals (MDGs) and Sustainable Development Goals (SDGs) [5]. Despite the efforts to expand access to universal education through the UBE in Nigeria, it is unlikely to achieve universal education in Nigeria by the end of 2015 [6].

There are still large number of out of school children with nearly half the population of all primary age children, with the worst affected demographics being children in the North, from rural areas, poor households, and female children [7]. This characterises the region with lower literacy and educational attainments and wider gender gap in educational attainment than the other region.

Studies have been conducted to determine the factors that affect children's education in Northern Nigeria [9], however, the existence of large disparity in the number of out-of-school children between North West and other regions of Nigeria needs to be explored. Thus, it is desirable to investigate the effects of children, household and state factors on the non-attendance of children to primary school in North West Nigeria.

This paper presents an analysis conducted to determine the factors affecting primary school nonattendance among children using the Nigeria Education Data Survey (NEDS) 2010 dataset [10]. The analysis uses multilevel logistic models to enable the estimation of factors at children, household and state levels that affects primary schooling in North West Nigeria.

\section{Factors Influencing Primary School Non-attendance}

Numerous factors have been reported to affect the primary schooling of children particularly in developing countries. These factors can be classified as child, household and state factors.

\subsection{Child Factors}

Child gender plays an important role in children's schooling, because most parents tend to give preference to gender by favouring male over female children [13]. The primary schooling of female children is negatively affected due to unavailability of labour force for women after schooling and some cultural norms of keeping female children at home to learn domestic skills necessary for being successful 
housewives [24]. Similarly, Abdul et al. [13] noted that female children in some parts of Northern Nigeria are traditionally often expected to remain at home with their mothers in order to learn domestic activities and other chores, such as cooking, sweeping, hairweaving, and dye production. The involvement of children in household chores affect female children more than male children, because female children are expected to stay at home and help with housework or babysit the younger siblings, which makes it difficult for them to attend school in Uganda [14]. Some societies also have the perception that female children after marriage often live in the families of their husbands and therefore, parents may prefer to invest in the education of boys especially if the female children are having a higher number of brothers [18]. Furthermore, children age also influences their primary schooling, because parents give preference to younger siblings over older siblings [18]. This is because the older children do the household chores, work in farm or contribute to the household income by earning some extra money in order to provide opportunities for younger children to attend school [13]. However, other studies have shown that the negative effect of large number of siblings on the schooling of older children in a household does not always hold in every family and society [17]. This is because in an extended family, where relatives help out in the household and add to the household income it makes it easier for children to go to school [21]. Kazeem et al. [8] also reported that, in Nigeria, children who have at least two older brothers/sisters have higher likelihood of attending school than children who have no older brothers/sisters. Besides gender and age, the presence or absence of parents in the household also influences children's primary schooling. Parents tend to give more priority to their own children when it comes to schooling, which increases the chances of not attending school by non-biological children [20, 21]. Kate et al. [21] also reported that the perceived preferential schooling of biological over foster children has increased the unwillingness of parents to entrust their children to foster parents.

\subsection{Household Factors}

Household factors that were found to influence primary school non-attendance are household wealth, parental education, parental perception, culture/religion and whether parents are present in a household. During the period of schooling, the income generated by a child to the household is less than when the child is not in school [24]. This make parents put into consideration the direct and indirect cost of school and the opportunity cost forgone when the child is in school [24]. As for parental level of education, children that are from non-educated households are more likely not to attend and stay in school [24]. Therefore, it is expected that parents with higher levels of education tend to support higher levels of educational participation for their children. Additionally, mother's level of education also plays an important role on educational enrolment of female children [25].

Besides household wealth and parental levels of education, culture may also be a determinant of primary school non-attendance among children. Studies have shown that culture creates female subordination, especially in areas with patriarchal system. In these areas, patriarchy prescribes the role of a female in society as a wife and mother [26]. Patriarchal societies are also mostly found in places where religions are dominating, and thus they are often seen as using religion in discriminating against women, thereby creating huge gender inequalities [9]. In some part of Northern Nigeria, female children are prevented from attending school because their households and families believe that formal education interferes with the traditional way of life [9].

\subsection{State Factors}

State factors such as residence type and distance to nearest school are important determinants of children's primary education. With regards to residence type, rural parents mainly work in subsistence farming and as such they may not see the value of their children's education because there are no job opportunities within their locality [15]. In addition, rural parents in some developing nations perceive that formal schooling may lead to the outmigration of their children to urban places [29]. However, in urban areas, there are employment opportunities that encourage parents to send their children to school. Urban areas also have adequate and good roads and transport infrastructure that are better than those in rural areas These facilitates access to schools, thereby influencing urban parents to send their children to school more than their rural counterparts [24]. Longer distance to nearest school might negatively affect children's primary schooling. The negative effect of longer distance to nearest school is more likely to be severe on the schooling of female children due to safety concerns, especially when a female child reaches puberty $[11,24]$.

Furthermore, school quality determines whether children attend primary school. Parents often realize that their children gain more from higher quality education and are therefore more willing to send them to school when they perceive the quality of education to be better [24]. Several quality indicators have been accredited with a negative impact on educational attainment, such as poor school facilities, under-qualified teachers and teacher absence [24]. 


\section{Variables}

The data for North West Nigeria were extracted from the NEDS 2010 dataset [10]. The data comprises 7390 primary school children aged 6-11 years across 823 households in the region, with 3689 females, and 3657 males. The response is a dummy variable indicating whether a child is attending (0) or not attending (1) primary school. At the children level, the independent variables used are age, gender and family structure. Primary school age (6 to 11 year olds) is measured as early primary (0), middle primary (1) and late primary (3) for 6-7 year olds, 89 year olds and 10 to 11 year olds respectively. Family structure is a dummy variable measured as biological child (0) or non-biological child (1). At the household and context level, parental education is measured as no education (0), some primary (1) and some secondary (2). Household wealth is measured as low (0), middle (1) and high (2) quintiles. Religion is measured as Islam (0) and Christianity (1). Parental survivorship (father alive, father live in household) is measured as yes (0) or no (1). School decision making is measured as father (0) or both parents (1). Parental perception regarding distance to school, travel to school unsafe, children unsafe at school, poor school facilities, child not interesting, child too young and sale/hawking are measured as yes (0) or no (1). Household location is measured as rural (0) or urban (1) and distance to the nearest primary school is measured as less than one kilometre (0) and one kilometre and above (1). The categories measured as (0) are used as reference category for their relevant variables.

\section{Model Development}

The method of estimation use to determine the effects of factors at children, household and context levels is a three-level multilevel logistic model [30]. A simple form of multilevel logistic model is presented in equation 1 .

$$
\operatorname{logit}(y)=\left(\frac{p}{1-p}\right)=\beta_{0}+\beta_{1} x_{\mathrm{i} j}+\delta_{j}
$$

Where $\beta 0$ is the log-odds that $y=1, \beta 1$ is the effect on log-odds of 1-unit increase in $\mathrm{x}$ for individuals in same group, often referred to as cluster-specific effect of $x$. Therefore exp $(\beta 1)$ is an odds ratio, comparing odds for individuals spaced 1-unit apart on $\mathrm{x}$ but in the same group. $\delta \mathrm{j}$ is the effect of being in group $\mathrm{j}$ on the log-odds that $\mathrm{y}=1$ which is also known as a level 2 residual.

Thus, the multilevel model for primary school non-attendance can be constructed as presented in equation 2 .

$$
\begin{aligned}
\operatorname{logit}(y)=\beta_{0}+ & \beta_{1} x_{\mathrm{i} j k}+\beta_{1} x_{2 j k} \\
& +\beta_{1} x_{3 j k}+\delta_{j}+\delta_{j k}
\end{aligned}
$$

where $\mathrm{X}_{1}, \mathrm{X}_{2}, \mathrm{X}_{3}$ are the sets of predictors that represents child, household and state factors respectively. $\delta_{1 \mathrm{j}}$ and $\delta_{\mathrm{jk}}$ are the household and state level effects. $\mathrm{P}$ is the probability that non-attendance is $1.1-\mathrm{P}$ is the probability that non-attendance ( ATD) is 0 . Therefore

$$
P=\frac{e^{\beta_{0}+\beta_{1} X_{1}+\beta_{2} X_{2}+\beta_{3} X_{3}}}{1+e^{\beta_{0}+\beta_{1} X_{1}+\beta_{2} X_{2}+\beta_{3} X_{3}}}
$$

\section{Results}

Table 1 presents the coefficients (B) and odd ratios $(\operatorname{Exp}(\mathrm{B}))$ of the multilevel logistic regression analysis conducted. The estimations were conducted using four different models. Model 1 is a null model that has no any explanatory variable. The estimated inter-class correlation coefficients (ICC) show that the proportion of variances explained at child, household and state levels are 52\%, 17\% and 30\% respectively. Then the proportion of the variance explained at level 1 decreased by $1 \%$ and increased by $1 \%$ at household and state levels. After adding household factors (Model 3), the proportion of variance that can be attributed by levels 1 and 2 increased by $11 \%$ and $2 \%$ respectively while the proportion variance explained by level 3 decreased by $13 \%$. The proportion of the variance explained remained the same after adding state factors (Model 4).

The results for child factors (male, mid and late primary age and relationship) have negative relationship with primary school non-attendance as shown in Model 4. This showed that males and older children have lower likelihood of primary school non-attendance than females and younger children respectively. The results also showed that being a non-biological child increases the likelihood of primary school non-attendance, because the odd ratio is greater than 1 . In addition, the factors at household level showed lower likelihood of primary school non-attendance for Christian children than their Muslim counterpart, because they have $14 \%$ lower chances of primary school non-attendance than Muslim children. However, this might be due to higher population of Muslims in North West Nigeria. The household factors also indicated that children in North West Nigeria have higher likelihood of nonattendance if they have uneducated parents or come from low wealth quintile, than children with educated parents or those from higher wealth index. Also, parents who perceive that it is unsafe for their children to travel to primary school and teachers 
Table 1. Coefficient and Odd ratios of multilevel logistic Regression Model with Non-attendance as Dependent Variable

\begin{tabular}{|c|c|c|c|c|c|c|c|}
\hline \multirow[b]{2}{*}{ Variables } & Model 1 & \multicolumn{2}{|c|}{ Model 2} & \multicolumn{2}{|c|}{ Model 3} & \multicolumn{2}{|c|}{ Model 4} \\
\hline & $B \quad \operatorname{Exp}(B)$ & $\boldsymbol{B}$ & $\operatorname{Exp}(B)$ & $\boldsymbol{B}$ & $\operatorname{Exp}(B)$ & $\boldsymbol{B}$ & $\operatorname{Exp}(B)$ \\
\hline \multicolumn{8}{|l|}{ Children Characteristics } \\
\hline Gender $=$ Male & & $-0.55 * *$ & 0.58 & $-0.62 * *$ & 0.54 & $-0.62 * *$ & 0.54 \\
\hline Age $=$ Late Primary & & $-0.51 * *$ & 0.60 & $-0.60 * *$ & 0.55 & $-0.59 * *$ & 0.55 \\
\hline Age $=$ Mid Primary & & $-0.44 * *$ & 0.65 & $-0.55 * *$ & 0.58 & $-0.55 * *$ & 0.58 \\
\hline Non-biological Child & & $-0.14^{*}$ & 0.87 & 0.03 & 1.03 & 0.04 & 1.04 \\
\hline \multicolumn{8}{|l|}{ Household Characteristics } \\
\hline \multicolumn{8}{|l|}{ Religion } \\
\hline Christianity & & & & $-1.97 * *$ & 0.14 & $-1.93 * *$ & 0.15 \\
\hline \multicolumn{8}{|l|}{ Parental Education } \\
\hline Some Secondary & & & & $-2.13 * *$ & 0.12 & $-2.05 * *$ & 0.13 \\
\hline Some Primary & & & & $-1.24 * *$ & 0.29 & $-1.23 * *$ & 0.29 \\
\hline \multicolumn{8}{|l|}{ Wealth } \\
\hline High Index & & & & $-1.68 * *$ & 0.19 & $-1.53 * *$ & 0.22 \\
\hline Middle Index & & & & $-1.00 * *$ & 0.37 & $-0.91 * *$ & 0.40 \\
\hline \multicolumn{8}{|l|}{ Father lives in Household } \\
\hline No & & & & $-0.37 *$ & 0.69 & $-0.38^{*}$ & 0.69 \\
\hline \multicolumn{8}{|l|}{ Parental Perception } \\
\hline Distance $=$ No & & & & 0.071 & 1.07 & 0.10 & 1.11 \\
\hline Travel Safety $=$ No & & & & $-0.43 * *$ & 0.65 & $-0.41 * *$ & 0.66 \\
\hline Teacher performance $=$ No & & & & $-0.60 * *$ & 0.55 & $-0.60 * *$ & 0.55 \\
\hline Unsafe at school $=$ No & & & & $0.38 * *$ & 1.46 & $0.35 *$ & 1.42 \\
\hline Poor facility $=$ No & & & & 0.04 & 1.04 & 0.04 & 1.04 \\
\hline Pupil uninterested $=$ No & & & & $0.28 *$ & 1.33 & $0.28 *$ & 1.33 \\
\hline Pupil Too Young $=$ No & & & & $0.21 *$ & 1.23 & $0.19 *$ & 1.21 \\
\hline Sales and Hawking $=$ No & & & & $0.23 *$ & 1.25 & $0.23 *$ & 1.26 \\
\hline \multicolumn{8}{|l|}{ Contextual Characteristics } \\
\hline \multicolumn{8}{|l|}{ Residence type } \\
\hline Urban & & & & & & $-0.23 *$ & 0.79 \\
\hline $\begin{array}{l}\text { Distance to school } \\
\qquad 1 \mathrm{Km} \text { and Above }\end{array}$ & \multicolumn{6}{|c|}{ Distance to school } & 2.44 \\
\hline \multicolumn{8}{|l|}{ ICC } \\
\hline Level 1 & 0.52 & 0.5 & & 0. & & 0.6 & \\
\hline Level 2 & 0.17 & 0.1 & & 0. & & 0.2 & \\
\hline Level 3 & 0.30 & 0.3 & & 0. & & 0.1 & \\
\hline Number of Observations & 7390 & 739 & & 73 & & 73 & \\
\hline
\end{tabular}

$* * \mathrm{p}<0.01 * \mathrm{p}<0.05$

perform poorly are more likely not send their children to primary school. It should however be noted that parental perception towards distance to school, children safety at school, poor school facility, pupil uninterested or being too young and involving children in sales/hawking do not influence primary school non-attendance in North West Nigeria. In addition, not having a father in household does not influence the likelihood of primary school nonattendance. For state factors, it is evident that urban 
children are less likely not to attend primary school than their rural counterparts. Also, children living one kilometre or higher from nearest primary school are also more likely not to attend primary school.

The results further showed that household factors affect the influence of child factors towards primary school non-attendance. This is because the inclusion of household factors in Model 3 reduces the likelihood of non-attendance by $4 \%, 5 \%$ and $7 \%$ for male, mid primary age and late primary age children respectively. This means the reduction in the likelihoods of not attending primary school by male and older children is accounted by at least one of the household factors. Further, the addition of state factors increased the likelihood of not attending primary school by Christian children to $15 \%$. The addition also increased the likelihood of primary school non-attendance for children whose parents has some secondary education, and those that belong the mid and high wealth quintiles to $13 \%, 40 \%$ and $22 \%$ respectively. Adding state factors also increased the likelihood of not attending primary school for children whose parents perceived that it is unsafe to travel to school by $1 \%$.

Table 2 presents the predicted probability of primary school non-attendance for a child in North West Nigeria. The results showed that the predicted probabilities of primary school non-attendance for a female child and a male child are $82 \%$ and $71 \%$ respectively. This shows the existence of gender difference in primary school attendance in the region. The results also showed that a child in early primary school age group has higher probability of not attending primary than a child in either mid or late primary age groups. However, being a nonbiological child does not increase the probability of primary school non-attendance over a biological child. Additionally, the results showed that the probability of primary school non-attendance of a child in Muslim household doubles the probability of primary school non-attendance of a child from Christian household. The results also showed that the predicted probability of primary school nonattendance decreased with increasing level of parental education and household wealth index. The results further showed that father's presence in a household reduces the probability of primary school non-attendance in North West Nigeria. For the state factors, the results showed a slightly lower probability of primary school non-attendance for urban child than rural child. The results also showed that a child who is living father from the nearest school has higher probability of primary school nonattendance than a child living closer to school.

Generally, the odds and probabilities of primary school non-attendance in North West Nigeria showed that the main factors that influence primary school non-attendance in the region are age and gender of children, parental education, wealth teacher performance (as perceived by parents) and distance to school.

Table 2. Predicted Probability of Primary School Non-attendance of a Child in North West Nigeria According to Child, Household and State Factors

\begin{tabular}{|c|c|}
\hline Factors & Predicted Probability \\
\hline \multicolumn{2}{|l|}{ Gender } \\
\hline Female & 0.82 \\
\hline Male & 0.71 \\
\hline \multicolumn{2}{|l|}{ Age } \\
\hline Late Primary Age & 0.72 \\
\hline Mid Primary Age & 0.73 \\
\hline Early Primary Age & 0.82 \\
\hline \multicolumn{2}{|l|}{ Relationship to Child } \\
\hline Biological & 0.82 \\
\hline Non-biological & 0.83 \\
\hline \multicolumn{2}{|l|}{ Religion } \\
\hline Christianity & 0.40 \\
\hline Islam & 0.82 \\
\hline \multicolumn{2}{|l|}{ Parental Education } \\
\hline Some Secondary & 0.38 \\
\hline Some Primary & 0.57 \\
\hline No Education & 0.82 \\
\hline \multicolumn{2}{|l|}{ Wealth Index } \\
\hline High & 0.50 \\
\hline Middle & 0.65 \\
\hline Low & 0.82 \\
\hline \multicolumn{2}{|l|}{ Father in Household } \\
\hline Yes & 0.76 \\
\hline No & 0.82 \\
\hline \multicolumn{2}{|l|}{ Residence Type } \\
\hline Urban & 0.78 \\
\hline Rural & 0.82 \\
\hline \multicolumn{2}{|l|}{ Distance to School } \\
\hline Less than $1 \mathrm{Km}$ & 0.82 \\
\hline $1 \mathrm{Km}$ and Above & 0.92 \\
\hline
\end{tabular}

For the negative effect of having uneducated parents, the possible reason is due to their inability to attain any level of education, as such they do not have the awareness of the value of education and therefore exert little or no effort in educating their children. For the effect of wealth, the findings indicated that parents in the low wealth quintile will likely not send their children to school because they cannot afford the direct and indirect cost of school. This is particularly strong for those rural children because most of them are in low wealth quintile and 
live farther from the nearest school and their parents find it difficult to handle the cost of transporting them children to school.

\section{Conclusion}

A multilevel logistic regression analysis was conducted to determine the effects of factors at child, household and state levels that influence primary school non-attendance among children in North West Nigeria. The analysis was conducted by nesting children in households, which are then nested in states.

The effects of children factors showed that gender has influence on the likelihood of not attending primary school by female children than their male counterparts. The outcome also indicated that child age influences the likelihood of not sending younger children to primary school, which is consistent with findings reported in [9, and 11]. However, the findings showed that not having a father in household do not negatively affects the likelihood of primary schooling in North West Nigeria. Furthermore, the household and state factors also have different levels of influences on primary school non-attendance. The effect of religion showed that Muslim children are more likely not to attend primary than their Christian counterpart in the region under study. The findings also showed that having uneducated parents or being in the low wealth quintile strongly influence the chances of not attending primary school in North West Nigeria. Additionally, the findings showed that rural children and those living farther from a nearest primary school are more likely not to attend primary school. Similarly, parents also perceived that it is unsafe to send children to primary school, which also increases the chances of not attending primary school. The possible explanation for these effects is, although education should be free for all children, parents in the low wealth quintile that are mainly living in rural areas and farther from the nearest primary school, cannot bear the cost of transportation and therefore not willing to send their children to school due to distance.

Generally, the findings suggest that children's age and gender, parental level of education, wealth quintile, teacher performance and availability of schools, within close proximity are the main determinants of primary school non-attendance in North West Nigeria. The findings also indicate that parental education and wealth affects how children and state factors influence primary school nonattendance in North West Nigeria. This means that having educated parents and more wealth have the potentials to significantly reduce the rate of primary school non-attendance. In addition, having more schools closer to communities particular in rural areas will also further reduce the rate of primary school non-attendance irrespective of children's gender and age. Finally, the overall findings have shown that educating people about the benefit of education and having primary school closer to communities will have great impact on reducing the rate of primary school non-attendance.

\section{References}

[1] UNESCO, 2012. Education and Skills for Inclusive and Sustainable Development Beyond 2015.

[4] UNESCO, 2011. Global Education Digest Regional Profile: Sub-Saharan Africa. UNESCO Institute of Statistics.

[5] UN, 2015. Sustainable Development Goals.

[6] UNESCO, 2011. Global Education Digest Regional Profile: Sub-Saharan Africa. UNESCO Institute of Statistics.

[7] ESSPIN, 2014. Annual Report 2013-2014. Report Number: Esspin 609 Accessed from https://Www.Esspin.Org/Reports/.../341-File-EsspinAnnual-Report2013-2014.Pd

[8] Kazeem, A., Jensen, L. and Stokes, C.S., 2010. School Attendance in Nigeria: Understanding the Impact and Intersection of Gender, Urban-Rural Residence and Socioeconomic Status. Comparative Education Review, 54(2), pp.295.

[9] Antoninis, M., 2014. Tackling the Largest Global Education Challenge? Secular and Religious Education in Northern Nigeria. World Development, 59, pp. 82-92.

[10] NPC (National Population Commission), 2010. Nigeria Education Data Survey. Abuja, Nigeria: National Population Commission.

[11] Smits, J. and J. Huisman, 2013. Determinants of Educational Participation and Gender Differences in Education in Six Arab Countries. Acta Sociologica, 56(4), pp.325-346.

[13] Abdul, M. M., Adeleke, O., Adeyey, O., Babalola, A., Eyo, E., Ibrahim, M.T., VokeIghorodje, M., and Onose, M., 2014. Analysis of the History, Organization and Challenges of Feminism in Nigeria. Project 10-cap1-0863. "Young Women, Empowerment and Development in Sub-Saharan Africa. Spanish International Cooperation for Development.

[14] Namukwaya, V. A., and Kibirige, I., 2014. Factors Affecting Primary School Enrolment and 
Retention of Pupils in Kotido District, Uganda. Mediterranean Journal of Social Sciences, 5(8), pp. 423.

[15] Huisman, J. and Smits, J., 2009. Effects of Household and District-Level Factors on Primary School Enrolment in 30 Developing Countries. World Development, 37(1), pp. 179-193.

[17] Estudillo, J. P., Sawada, Y., and Otsuka, K., 2009. The changing determinants of schooling investments: evidence from villages in the Philippines, 1985-89 and 2002-04. The Journal of Development Studies, 45(3), pp. 391-411.

[18] Gurmu, E., and Etana, D., 2013, "Socioeconomic and Demographic Determinants of Children's Primary School Enrolment in Ethiopia", Eastern Africa Social Science Research Review, 29(1), pp.1-30.

[21] Pickett, K. and Vanderbloemen, L., 2015 Mind the Gap: tackling social and educational inequality. York:

Cambridge Primary Review Trust.

[24] Smits, J. and J. Huisman, 2013. Determinants of Educational Participation and Gender Differences in Education in Six Arab Countries. Acta Sociologica, 56(4), pp. 325-346.

[25] Johnston, D.W. and Shields, S.C.K.M.A., 2015. Who Makes The Financial Decisions? IntraHousehold Evidence from Panel Data.

[26] Shahidul, S. M., 2013. Mothers' Participation in the Household Decision and Daughters' Education. Working Paper Series No.7. Centre for the Study Of Social Stratification and Inequality (CSSI), Japan.

[29] Lakin, M., and Gasperini, L., 2003. Basic education in rural areas: status, issues, and prospects. Education for Rural Development: Towards New Policy Responses, FAO/UNESCO. Leach, Fiona 2006. "Researching Gender Violence in Schools." World Development 34, pp. 1129-1147.

[30] Snijders, T.A.B., and Bosker, R J., 2012. Multilevel Analysis: An Introduction to Basic and Advanced Multilevel Modeling, second edition. Sage Publishers, London. 